This paper was published in IET Electrical Systems in Transportation, 2014, doi 10.1049/iet-est.2014.0007, and is available at:

http://digital-library.theiet.org/content/journals/10.1049/iet-est.2014.0007

R. Todd, V. Valdivia, V. F.J. Bryan, A. Barrado, A. Lázaro, A.J. Forsyth, "Behavioural modelling of a switched reluctance motor drive for aircraft power systems," IET Electrical Systems in Transportation, vol. 4, no. 4, pp.107-113, 2014 doi: 10.1049/iet-est.2014.0007

(C) 2014 IET. Personal use of this material is permitted. Permission from the IET must be obtained for all other uses, in any current or future media, including reprinting/republishing this material for advertising or promotional purposes, creating new collective works, for resale or redistribution to servers or lists, or reuse of any copyrighted component of this work in other works. 


\title{
Behavioural Modelling of a Switched Reluctance Motor Drive for Aircraft Power Systems
}

\author{
R. Todd", V. Valdivia ${ }^{\dagger}$, F.J. Bryan", A. Barrado ${ }^{\prime}$, A. Lázaro ${ }^{*}$, A.J. Forsyth* \\ "School of Electrical \& Electronic Engineering, The University of Manchester, UK \\ ${ }^{\dagger}$ Carlos III University of Madrid, Spain
}

\begin{abstract}
A system-level behavioural modelling technique is described for a switched reluctance motor drive (SRMD). The model enables simple and efficient analysis or simulation of multiple drive systems such as pumps, actuators and engine starters within a more-electric network for example on-board an aircraft. The behavioural model is based on a power balance analysis. The transfer functions in the model are parameterised from experimental tests on the drive system, resulting in a simple model that only reproduces the average behaviour of the input-output variables necessary for system-level analysis. No data from the manufacturer is required to develop the model. The technique is discussed and validated using an engine starter in an aircraft test facility.
\end{abstract}

Index Terms - Switched Reluctance Motor Drive, Aerospace, Modelling, System Identification

\section{INTRODUCTION}

A key part of the more-electric aircraft (MEA) concept is the removal of non-electrical power off-takes from the gas-engine, such as hydraulic and pneumatic systems. However, this creates a need for electrical alternatives to drive auxiliary equipment such as pumps, actuators and engine starters [1]-[4]. Switched reluctance motor drives (SRMDs) are one of the technologies under consideration for future aircraft systems due to their high power-density, robustness and fault tolerance, which are particularly important features for on-engine applications [5]-[9]. For the purposes of electrical system design and integration a system level modelling and simulation capability is required, enabling the behaviour of multiple switched reluctance motor drives plus the complete electrical system to be examined under all modes of operation, especially to identify dynamic interaction between subsystems and instability effects. 
Existing SRMD models [10]-[13] are inappropriate for system-level studies as they contain computationally intense internal operational details of the drive, and so result in excessive simulation times. To overcome the problem a system-level behavioural modelling method for a SRMD is presented in this paper. The model includes only the averaged input-output signals and is parameterised from straightforward experimental tests. Therefore, detailed knowledge of the internal workings of the drive is not required, allowing model parameterisation without assistance from the manufacturer. Furthermore, the model is simple, so reduced simulation times may be achieved.

One of the main challenges in developing a simplified, behavioural model for a complex motor drive is to represent accurately the key aspects of system behaviour across the range of operating conditions, which is achieved in this work through extensive characterisation tests and judicious choice of the model structure, including the use of look-up tables for system losses. At each stage of development the model complexity must be carefully traded against accuracy. In addition to the analysis and design of more-electric aircraft systems, the modelling techniques described in this paper will have applications in a range of other transport domains such as marine, automotive and rail, where SRMDs are also under consideration for traction and auxiliary functions.

\section{SYSTEM DESCRIPTION}

The engine starting system under consideration is shown in Fig. 1.a and comprises a commercial SRMD from SR Drives, which is coupled to a gas-engine emulator. The SRMD is a three phase twelve stator pole eight rotor pole design and the interface converter is a standard half-bridge topology. The SRMD is also capable of generator operation when the engine is running. A bi-directional grid-tied converter behaves as an auxiliary power unit (APU) to provide power to the DC-bus during engine starting. The APU control was regulating the DC bus to $540 \mathrm{~V}$ and the APU droop control was active which provides a linear, $20 \mathrm{~V}$ drop in bus voltage as the APU power output increases from zero to maximum [5]. Fig. 1.b shows a simple block diagram for the SRMD. The output, $v_{c o m}$, of speed regulator $R_{\omega}$ passes to the 'Driver' to set the 
commutation angles and current control levels used to command the power electronics. $\omega_{\text {ref }}$ is the speed reference from the engine starter and $K_{\omega}$ represents the speed sensor. A torque transducer, not shown in Fig. 1 , is fitted between the emulator and the SRM to measure the load torque, $T_{\text {load, }}$ which is used in the model parameterisation, Section IV.

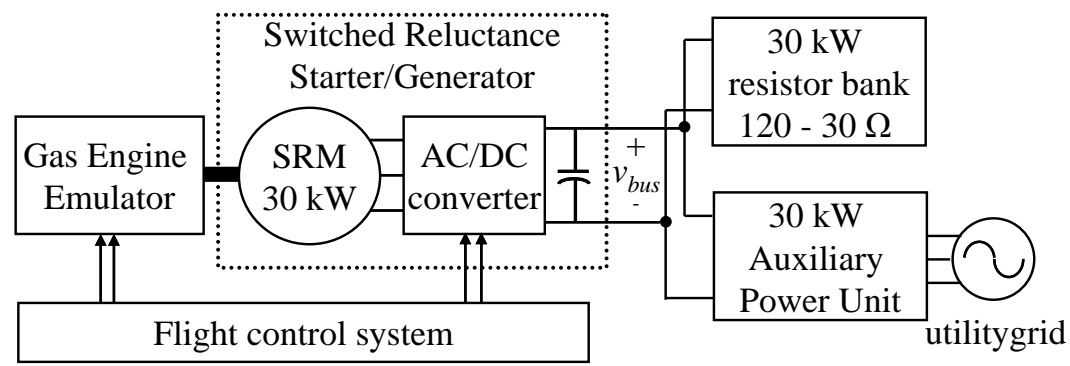

a. Overview of full experimental system

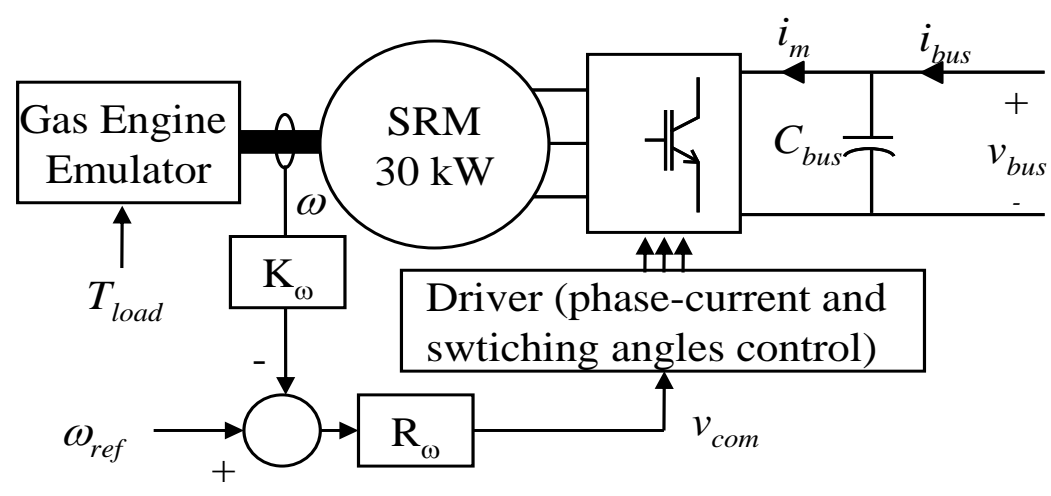

b. Overview of the switched reluctance motor drive system

Fig. 1 Experimental system under study

The flight control system in Fig. 1.a contains a thermodynamic and mechanical gas-engine model which commands the gas-engine emulator (an electric drive) to replicate the drag characteristics and starting behaviour of the engine. The SRMD enables electric start of the engine, and experimental results for this are used for model validation in Section V. Once the engine start process is complete, the SRMD is disconnected from the DC bus and enabled as a generator. The SRMD model developed in this paper can be combined with the generator model in [14] to form a system-level model of the starter generator system; neither model can be used to describe both motor and generator operation. 


\section{MODELLING APPROACH}

The SRMD power hardware (machine and converter) in motoring mode is modelled as a controlled current sink $i_{m}$ in parallel with $C_{b u s}$, as shown in Fig. 2. The controlled current sink is regulated by a power balance block and the operation of the speed control loop is represented by the speed dynamics block; the implementation of both blocks is discussed in the remainder of this section.

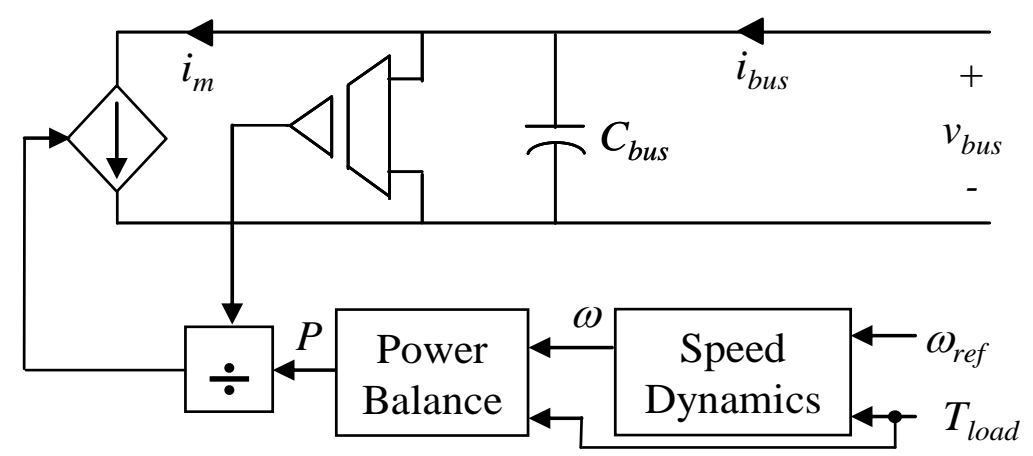

Fig. 2 Model schematic of SRMD

\section{A. Power balance block}

The SRMD power hardware (machine and converter) behaviour is expressed in this model, Fig. 2, by a power balance to command a current sink $i_{m}$ in parallel with $C_{b u s}$. The power balance determines the local average of the instantaneous electrical power $P$.

The instantaneous electrical power is obtained by first calculating the electromagnetic torque $T_{\text {elec }}$ from (1). The instantaneous mechanical power $P_{m}$ is calculated as the product of $T_{\text {elec }}$ and $\omega$.

$$
T_{\text {elec }}=T_{\text {load }}+J \frac{d \omega}{d t}+B \omega
$$

where $J$ is the total moment of inertia, $B$ is the friction coefficient and $\omega$ is the speed.

The local average of the instantaneous electrical power $P$ is then calculated by adding the electrical losses $P_{\text {loss-elec }}$ and the rate of change of stored electromagnetic energy $d E_{L} / d t$ to the mechanical power, $P_{m}$, giving (2). The $d E_{L} / d t$ term is neglected as the local average of the phase currents over an electrical cycle is zero [15]-[18]. 


$$
P=v_{\text {bus }} i_{m}=P_{m}+P_{\text {loss-elec }}+\frac{d E_{L}}{d t}
$$

Eqs. (2) can be rewritten using (1) and the definition for $P_{m}$ to give (3).

$$
P=\left[\omega\left(T_{\text {load }}+J \frac{d \omega}{d t}\right)+P_{\text {loss-total }}\right]
$$

where $P_{\text {loss-total }}=B \omega^{2}+P_{\text {loss-elec }}$ which is the total power losses of the SRMD.

The local average power $P(3)$ is a function of mechanical speed $\omega$ and torque $T_{\text {load }} P$ from (3) is then divided by $v_{\text {bus }}$ to obtain the machine current $i_{m}$.

\section{B. Speed dynamics block}

The small signal dynamics of the speed controller are represented by the block diagram in Fig. 3, where the mechanical dynamics are assumed to be described by (1). $R_{\omega}(s)$ is the speed regulator, and $K_{\omega}(s)$ is the speed sensor.

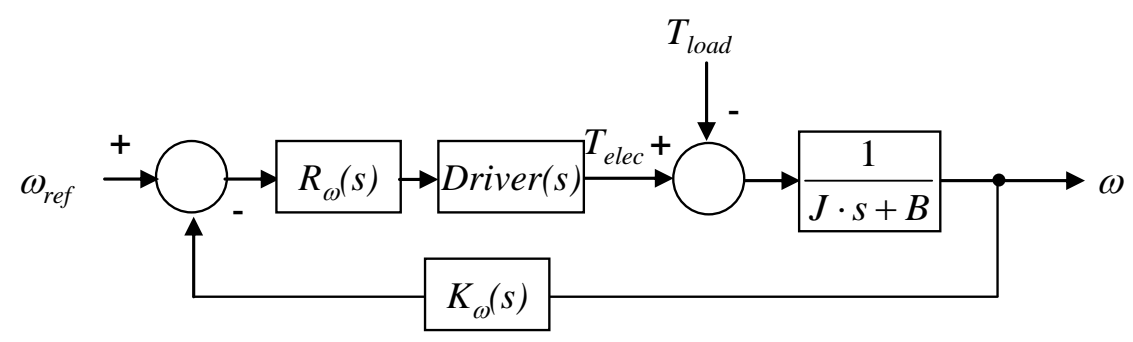

Fig. 3 Small-signal model of the speed control loop

From Fig. 3 the relationship between $\omega, T_{\text {load }}$ and $\omega_{\text {ref }}$ can be expressed as:

$$
\omega(s)=G_{\omega}(s) \omega_{r e f}(s)-G_{T}(s) T_{\text {load }}(s)
$$

where $G_{\omega}(s)$ is the closed-loop transfer function of the speed regulation and $G_{T}(s)$ is the closed-loop relationship between $T_{\text {load }}$ and $\omega . G_{\omega}(s)$ and $G_{T}(s)$ are designed and discussed in Section IV.

Fig. 3 illustrates a single speed control loop as used in the SRMD system, however, the exact structure of the speed control is not explicitly stated in this model; it is embedded in the speed dynamics block and so alternative controllers can only be implemented by modifying $G_{\omega}(s)$ and redesigning the speed dynamics 
block. The dynamics of the inner current control loop is embedded in the 'Driver' block in Fig. 3.

\section{MODEL PARAMETERISATION}

The parameterisation of the model uses only time domain measurements and parametric identification techniques [19], [20]. Section IV.A presents the SRMD power hardware model which is implemented as a power balance block. The speed controller is embedded in the speed dynamics block and is presented in Section IV.B.

\section{A. Power balance block}

The power balance block (3), shown in Fig. 2, is implemented as an equation, to determine the instantaneous mechanical power $P_{m}$, plus a look-up table to describe the electrical and mechanical losses. This approach enables the system dynamics to be captured over the full speed and torque range of the motor. The instantaneous mechanical power and power losses are determined in this section.

\section{1) Instantaneous mechanical power}

Measurements of speed and torque are available in both the experimental system and the simulation model and so both are used as inputs to the instantaneous mechanical power equation. Experimental tests are required to quantify the moment of inertia $J$ in the experimental system. The SRMD and engine emulated inertias are lumped into a single inertia in this model.

The total moment of inertia $J$ can be identified from a constant acceleration test. Fig. 4 shows the bus voltage $v_{b u s}$, the current drawn by the SRMD $i_{b u s}$ and the speed $n_{m}$ under a constant acceleration test up to $5,000 \mathrm{rpm}$. The reference speed signal is $n_{m-r e f}$. 


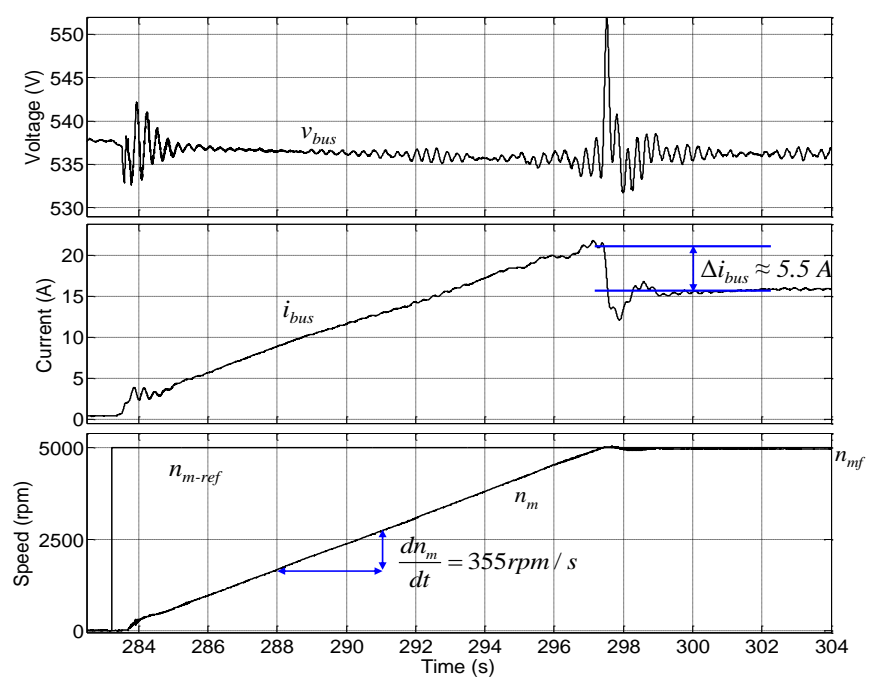

Fig. 4 Constant acceleration test from 0 to $5000 \mathrm{rpm}$ at constant $T_{\text {load }}=15 \mathrm{Nm}$

The instantaneous drop in bus current, $\Delta i_{b u s}$, as the machine achieves its final speed, is assumed to represent the instantaneous accelerating power at the final speed of 5,000 rpm. Therefore, the total moment of inertia $J$ may be estimated from:

$$
P_{b u s}=v_{\text {bus }} \Delta i_{\text {bus }}=J \omega_{f} \frac{d \omega}{d t}
$$

It is assumed that $\Delta i_{b u s} \approx \Delta i_{m}$, as the mechanical time constants are much slower than the electrical time constants.

To maximize $\Delta i_{b u s}$ a high acceleration rate $(355 \mathrm{rpm} / \mathrm{s}$ in Fig. 4) was used up to the maximum motoring speed of 5,000 rpm, and a constant load torque of $15 \mathrm{Nm}$ was imposed on the SRMD by the engine emulator dynamometer. The estimated total moment of inertia $J$ (SRMD and emulator dynamometer) from Fig. 4 is $0.15 \mathrm{~kg} \mathrm{~m}^{-2}$.

\section{2) Power losses}

The power losses are obtained from the difference between the input electrical power and the output mechanical power over the full motoring range of the SRMD. The calculated power losses, $P_{\text {loss-total }}$, from measured data for several operating points is shown in Fig. 5. The data in Fig. 5 is implemented in the model using a look-up table as a function of $T_{\text {load }}$ and $\omega$. 


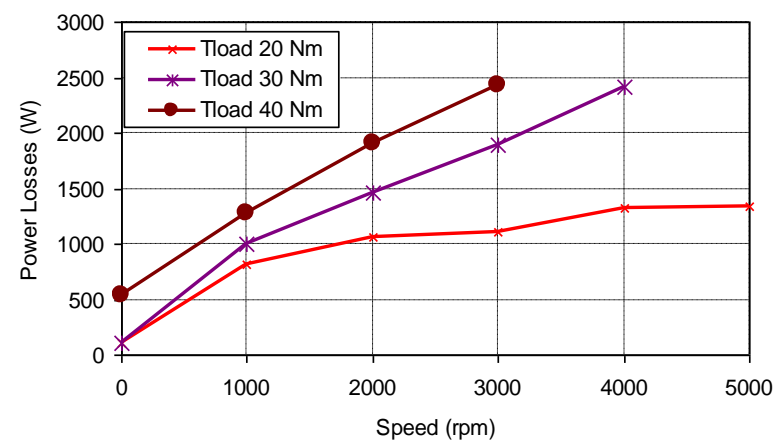

Fig. 5 Power losses as a function of load torque $T_{\text {load }}$ and speed $n_{m}$

\section{B. Speed dynamics block}

Transfer functions for $G_{\omega}(s)$ and $G_{T}(s)$ are required to define the speed dynamics of the SRMD. Any dynamic dependence on operating point is also analysed.

\section{1) Closed-loop speed transfer function $G_{\omega}(s)$}

Assuming constant load torque, then from (4) the dynamic relationship between the SRMD speed and the reference speed can be expressed as:

$$
G_{\omega}(s)=\left.\frac{\omega(s)}{\omega_{\text {ref }}(s)}\right|_{T_{\text {load }}(s)=0}
$$

$G_{\omega}(s)$ can be identified by applying a step to $\omega_{\text {ref }}$ while $T_{\text {load }}$ is constant. In (6), as a small-signal relationship is assumed, the initial steady-state component of $T_{\text {load }}$ is effectively removed and so set to zero. The parametric identification technique [19], [20] can be applied to the measured $\omega$ and $\omega_{\text {ref }}$ to determine $G_{\omega}(s)$.

Several step tests have been carried out over the full speed and torque envelope of the SRMD to determine the transfer function. The magnitude of the speed steps was relatively small $(1,000 \mathrm{rpm})$ to ensure approximately linear operation. The response of the SRMD to two 1,000 rpm steps is shown in Fig. 6. Fig. 6.a shows results for a 4,000 rpm to 5,000 rpm step at low torque, $T_{\text {load }}=5 \mathrm{Nm}$ and Fig. $6 . \mathrm{b}$ shows results for a lower speed step, 1,000 rpm to 2,000 rpm, but at higher torque $\left(T_{\text {load }}=40 \mathrm{Nm}\right)$. Although a step is applied, the signal received by the controller has an acceleration limit of $355 \mathrm{rpm} / \mathrm{s}$, shown by $n_{m}$ - 
reflim in Fig. 6. As can be seen in Fig. 6, the speed response is similar in both cases, so $G_{\omega}(s)$ can be assumed independent of $\omega$ and $T_{\text {load }}$. This is confirmed later in this section by analysing the frequency response of the identified transfer functions.

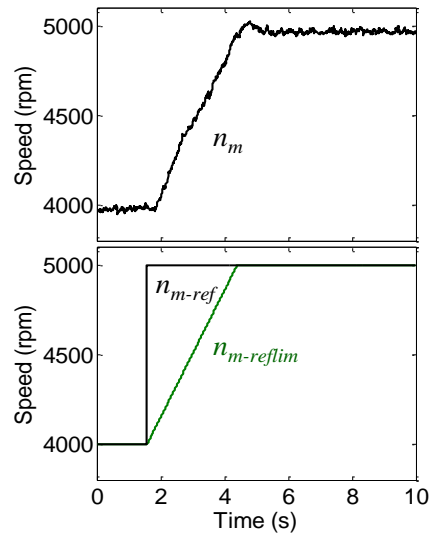

a. 4,000 rpm to $5,000 \mathrm{rpm}$ at

$T_{\text {load }}=10 \mathrm{Nm}$

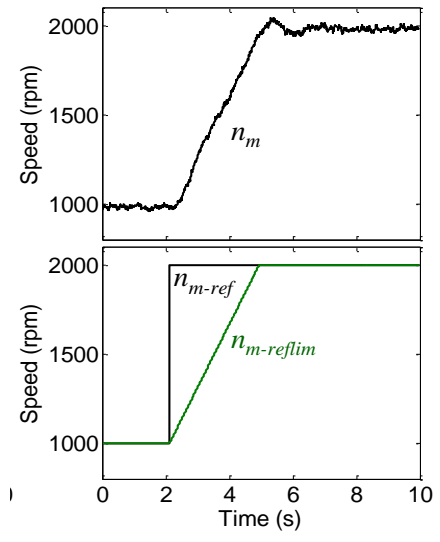

b. $1,000 \mathrm{rpm}$ to $2,000 \mathrm{rpm}$ at $T_{\text {load }}=40 \mathrm{Nm}$

Fig. 6 Speed responses for constant $T_{\text {load }}$

Transfer function models $G_{\omega}(s)$ are identified from both load torque tests. The rate limited speed $n_{m \text {-reflim }}$ is converted from rpm to $\mathrm{rad} / \mathrm{s}$, resulting in $\omega_{\text {reflim }}$, and used with $\omega$ to identify $G_{\omega}(s)$. The cost function COF is given by (7), which has been optimised using the " $e$ " function of MATLAB.

$$
C O F=\sum_{k=1}^{N}\left(\omega(k)-G_{\omega}(q) \omega_{r e f l i m}(k)\right)^{2}
$$

Two second order transfer functions have been identified (8) which yield good fitting results as shown in Fig. 7. In Fig. 7.a, the measured and model responses to the identification tests (after subtracting the initial steady-state values) are overlaid and give a correlation of $97 \%$ in both cases. The fitting results are evaluated using the "compare" function of MATLAB.

$$
\begin{aligned}
G_{\omega 10}(s) & =\frac{440.3 * 10^{-3} s^{2}+0.8901 s+19.12}{s^{2}+2.622 s+19.29} \\
G_{\omega 40}(s) & =\frac{4 \cdot 956 * 10^{-6} s^{2}+0.01982 s+19.82}{s^{2}+2.408 s+19.99}
\end{aligned}
$$



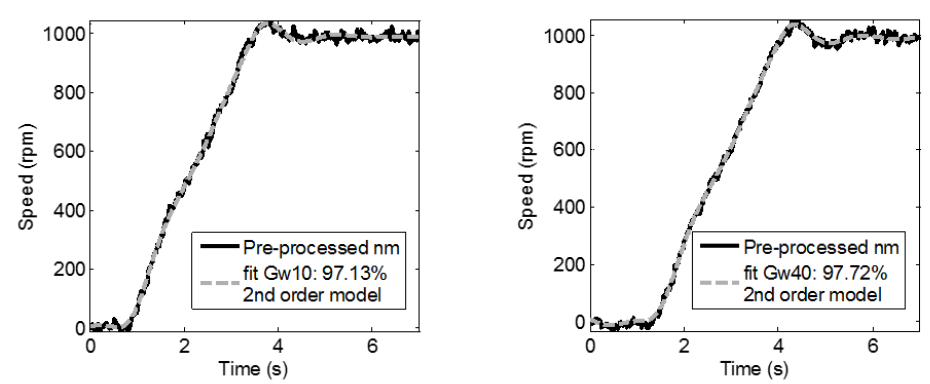

$$
G_{\omega 10}(10 \mathrm{Nm})
$$$$
G_{\omega 40}(40 \mathrm{Nm})
$$

a. Fitting results of $G_{\omega l 0}$ and $G_{\omega 40}$

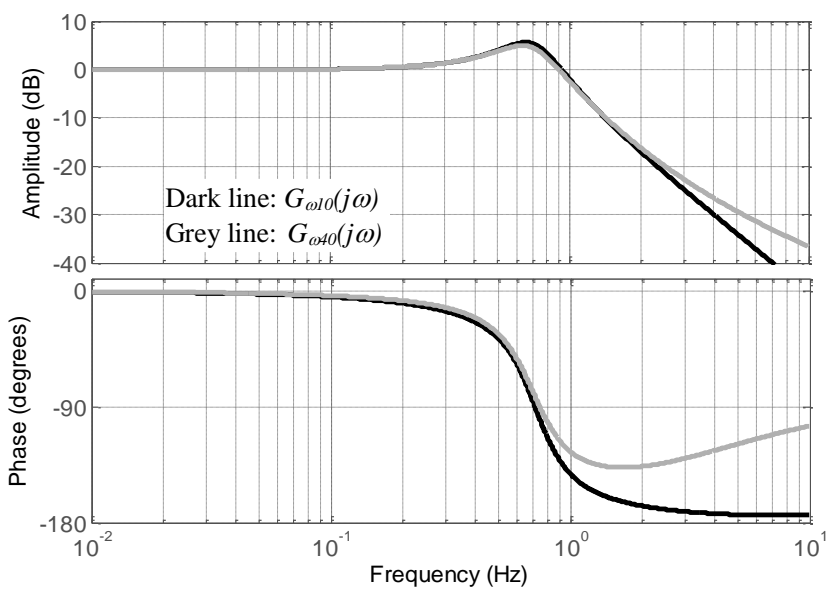

b. Frequency response of $G_{\omega}(j \omega)$ as a function of torque

Fig. 7 Performance of $G_{\omega}$ transfer functions (8)

The frequency response of both transfer functions (8) are compared in Fig. 7.b. Both frequency responses are similar and only slight differences are noticed above $1 \mathrm{~Hz}$, but considering the slew rate limit on $\omega_{\text {ref }}$ these differences can be neglected. Fig. 7.b confirms that $G_{\omega}(s)$ can be assumed independent of operating point.

\section{2) Load torque transfer function $G_{T}(s)$}

The transfer function representing the effect of $T_{\text {load }}$ on $\omega, G_{T}(s)$, can be determined from (9) if speed is constant in (4).

$$
G_{T}(s)=-\left.\frac{\omega(s)}{T_{\text {load }}(s)}\right|_{\omega_{\text {ref }}(s)=0}
$$


$G_{T}(s)$ can then be identified by using parametric identification on the results of a test when a step is applied to $T_{\text {load }}$ while the reference speed $\omega_{\text {ref }}$ is constant. In (9), as a small-signal relationship is assumed, the initial steady-state component of $\omega_{\text {ref }}$ is effectively removed and so set to zero. The transfer function $G_{T}(s)$ has been examined over the full speed and torque range of the SRMD.

The response of the SRMD to a $5 \mathrm{Nm} T_{\text {load }}$ step at two different operating speeds is shown in Fig. 8. Fig. 8.a shows the result of a torque step from $15 \mathrm{Nm}$ to $20 \mathrm{Nm}$ at a speed of 1,000 rpm. Fig. 8.b shows the test results for a torque step from a lower torque level but at higher speed (from $5 \mathrm{Nm}$ to $10 \mathrm{Nm}$ at 2,000 rpm).

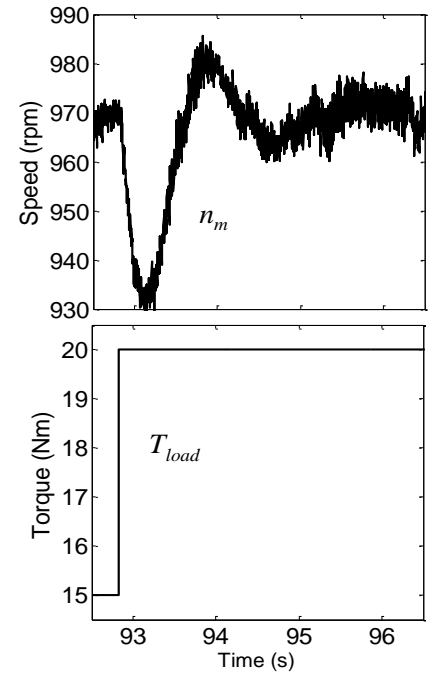

a. $15 \mathrm{Nm}$ to $20 \mathrm{Nm}$ step at

$n_{m-r e f}=1,000 \mathrm{rpm}$

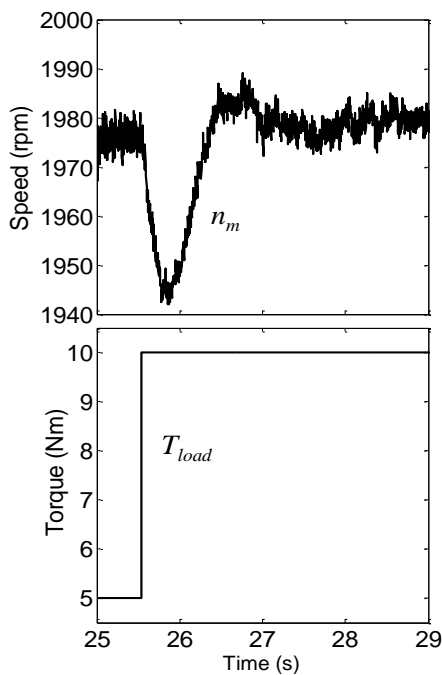

b. $5 \mathrm{Nm}$ to $10 \mathrm{Nm}$ step at

$$
n_{m-r e f}=2,000 \mathrm{rpm}
$$

Fig. 8 Speed responses for a $T_{\text {load }}$ step

The speed response is similar in both cases shown in Fig. 8. When $T_{\text {load }}$ increases the speed initially reduces due to the mismatch between electrical input and mechanical output power, the speed then returns to the reference value due to the operation of the speed controller. Whilst similar oscillation frequencies are observed in Fig. 8, slightly higher damping is evident in the test in Fig. 8.b, (reduced overshoot) suggesting $G_{T}(s)$ has a slight dependence on operating point. Both speed responses in Fig. 8 exhibit a steady-state error of less than $3 \%$, and have settling times of approximately $2.5 \mathrm{~s}$.

Transfer functions for $G_{T}(s)$ have been identified from both tests. The cost function to be optimised in 
this case is:

$$
C F=\sum_{k=1}^{N}\left(\omega(k)-G_{T}(q)\left(-T_{\text {load }}(k)\right)\right)^{2}
$$

Good identification results are achieved with third order transfer functions, as shown in Fig. 9.a. $G_{T 1000}$ and $G_{T 2000}$ correspond to the transfer functions identified at 1,000 rpm and 2,000 rpm, respectively, which are expressed in (11). The frequency responses of (11) are compared in Fig. 9.b, where it is seen that there is a slight difference in damping, with reduced damping being apparent at higher $T_{\text {load }}$. However, in the interests of model simplicity, then for this SRMD the slight nonlinearity can be neglected from a practical point of view.

$$
\begin{aligned}
G_{T 1000}(s) & =\frac{320.8 * 10^{-6} s^{3}+0.6416 s^{2}+320.8 s-0.6002}{s^{3}+62.39 s^{2}+204.3 s+1150} \\
G_{T 2000}(s) & =\frac{1.69 * 10^{-3} s^{3}+3.38 s^{2}+1690 s+7.036}{s^{3}+339.1 s^{2}+1306 s+5730}
\end{aligned}
$$

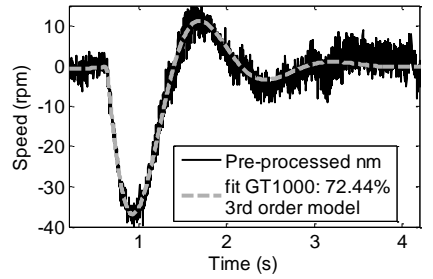

$G_{T 1000}(1,000 \mathrm{rpm})$

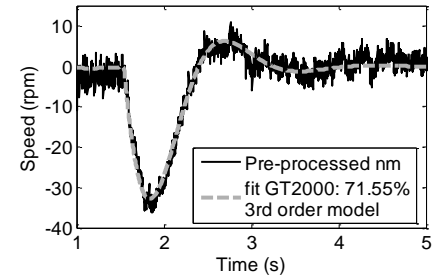

$G_{T 2000}(2,000 \mathrm{rpm})$

a. Fitting results of $G_{T 1000}$ and $G_{T 2000}$

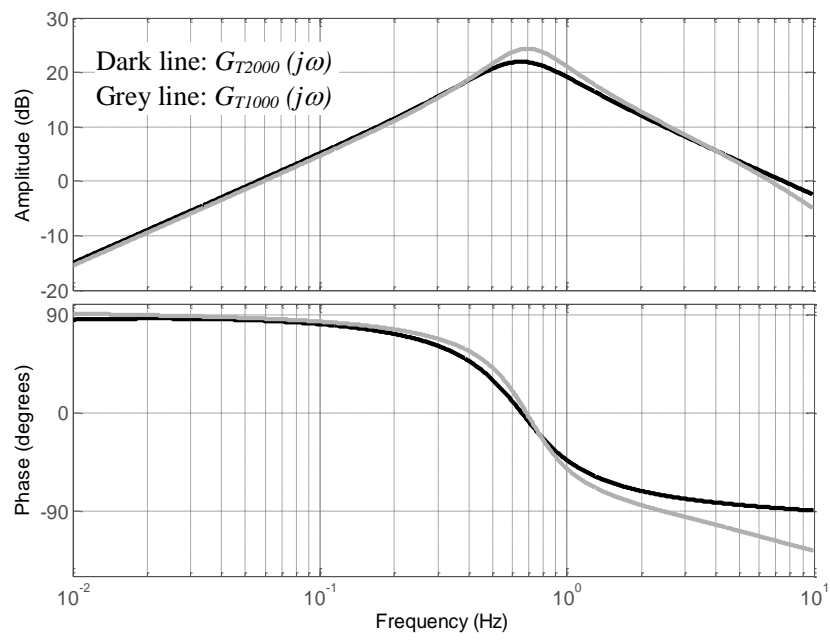

b. Frequency response of $G_{T}(j \omega)$ as a function of speed 
Fig. 9 Performance of $G_{\omega}$ transfer functions, (11)

If the experimental data shows significant difference in $G_{\omega}(s)$ and $G_{T}(s)$ with operating point, then the transfer functions in the behavioural model can be designed using a Polytopic approach [21], [22] to account for the dynamic dependence on operating point, this would however increase the model complexity.

\section{3) Model implementation}

The implementation of the speed dynamics block in Fig. 2, uses $G_{\omega}(s)=G_{\omega 10}$ from $(8), G_{T}(s)=G_{T 2000}$ from (11), plus a slew-rate limit block to account for the $355 \mathrm{rpm} / \mathrm{s}$ acceleration limit in the actual SRMD.

\section{MODEL VALIDATION}

The model of the SRMD has been implemented in the circuit simulator PSIM and a set of starting profiles have been experimentally tested to validate the simulation model using the setup in Fig. 1. Load torque $T_{\text {load }}$ and speed $n_{m-r e f}$ profiles are sent from the FCS to the gas-engine emulator and the SRMD, respectively, while the APU regulates the DC-bus to $540 \mathrm{~V}$. The equivalent simulation model of Fig. 1 uses the SRMD model developed in Section IV, with the APU represented as a fixed DC voltage in series with the APU output impedance; to complete the simulation model, a model of the APU is required.

\section{A. Modelling the auxiliary power unit}

The APU has been modelled using the black-box technique described in [22]. The model consists of a Thevenin network comprising a DC source and a transfer function output impedance $Z_{A P U}(s)$. The transfer function can be identified from a load step test.

The transient response of the APU is shown in Fig. 10.a and the large deviation in $v_{\text {bus }}$ when the $5 \mathrm{~kW}$ load is applied to the DC-bus implies that $Z_{A P U}$ is relatively large. The transfer function $Z_{A P U}(s)$ determined by applying parametric identification to $v_{b u s}$ and $i_{b u s}$ in Fig. 10.a is given by (12). The response of the identified impedance model and the measured response after pre-processing are compared in Fig. 10.b and 
the resulting fit is $96 \%$. The frequency response of (12) is plotted in Fig. 10.c, showing that it has a much higher natural frequency $(\sim 25 \mathrm{~Hz})$ than the speed dynamics transfer function in Fig. 7.b.

$$
Z_{A P U}(s)=\frac{0.43 s^{2}+8762 s+1003}{s^{2}+232.9 s+29 * 10^{3}}
$$

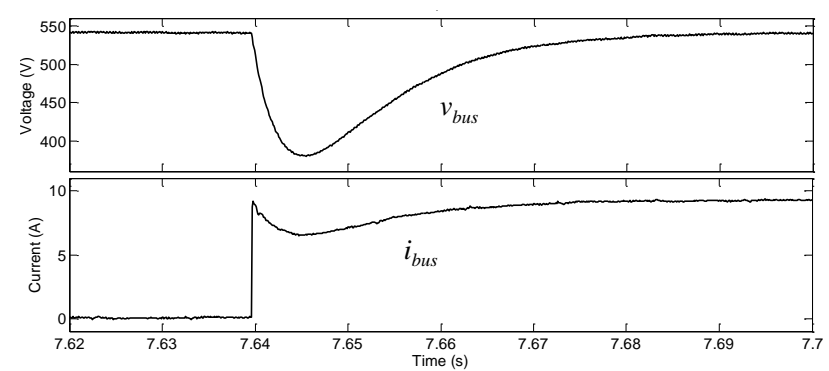

a. Transient response to $5 \mathrm{~kW}$ load step

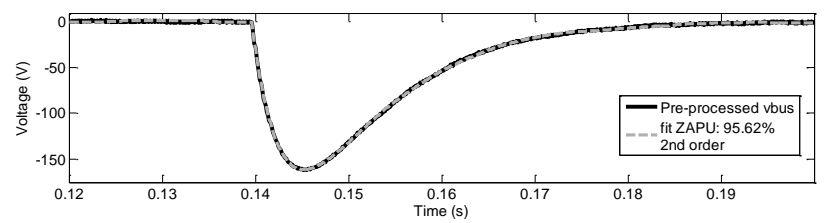

b. Fitting results of $Z_{A P U}(q)$

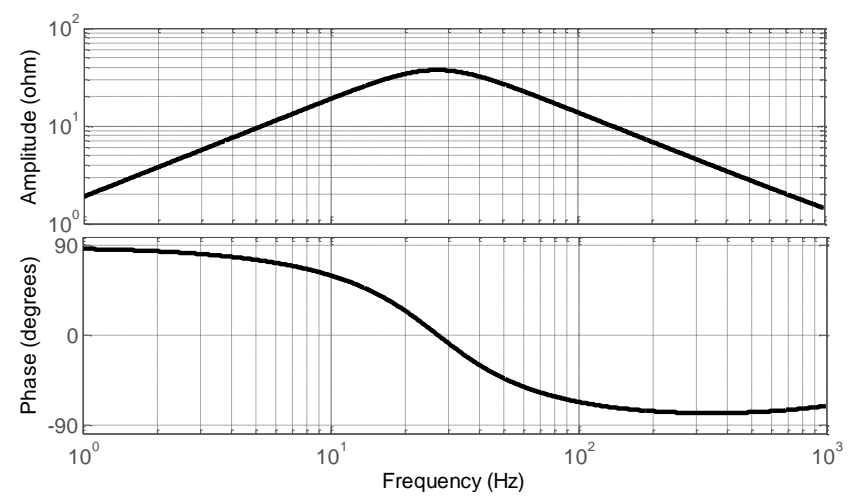

c. Bode plot of $Z_{A P U}$

Fig. 10 Identifying the output impedance of the APU $Z_{A P U}$

\section{B. Validation tests 1: Constant acceleration profile at constant load torque}

The first validation test consists of a constant acceleration profile of $100 \mathrm{rpm} / \mathrm{s}$ from 0 to $5,000 \mathrm{rpm}$ while the load torque is kept constant at $8 \mathrm{Nm}$. Fig. 11 shows a very good correlation between the actual response and the model response for DC-bus voltage, current and speed during both the transient and steady-state 
periods. The bus voltage reduces with increasing bus current due to the action of the APU's droop control [5].

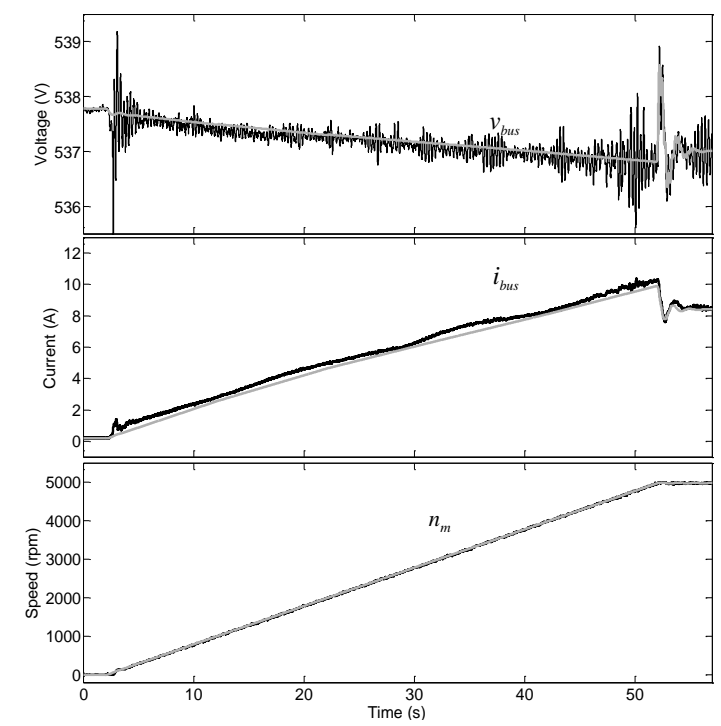

Fig. 11 Measured (black traces) and simulated response (grey traces) under a constant acceleration profile of $100 \mathrm{rpm} / \mathrm{s}$ at $T_{\text {load }}=8 \mathrm{Nm}$

\section{Validation test 2: Actual gas turbine starting profile}

The second validation test for the SRMD model is the electric start of the gas-engine. During the simplified starting process the SRMD accelerates the engine emulator against the drag torque of the engine (imposed by the engine emulator). The SRMD torque reduces once the engine has been ignited and accelerates up to ground idle speed. The SRMD is disconnected from the DC-bus once the engine is selfsustaining. A $2.5 \mathrm{~kW}$ background load (using the resistor bank shown in Fig. 1) was connected to the DCbus to represent electrical loads which must be on-line before the gas-engine can be started.

The comparison between the experimental measurements and the simulation results in Fig. 12 shows good correlation between the model response and the measurements. Dynamic interactions are noticeable as the bus voltage oscillates just after the maximum power level is reached. This is associated with a mildly unstable SRMD operating region which has been placed at a speed below ground idle for this engine. The SRMD safely passes through this unstable region and due to the difference between the electrical and mechanical time constants the engine is protected from the instability. As can be seen, the dynamic 
interactions are predicted by the model, with a higher oscillation being predicted by the simulation than was measured. The difference is due to additional damping in the test setup, for example from the inner current loop dynamics which are not explicitly accounted for in the model and the assumption that $v_{\text {bus }}$ can instantaneously change $i_{m}$ in the model, whereas in the experimental system there may be some delay, due to the current loop dynamics, which may damp the oscillation.

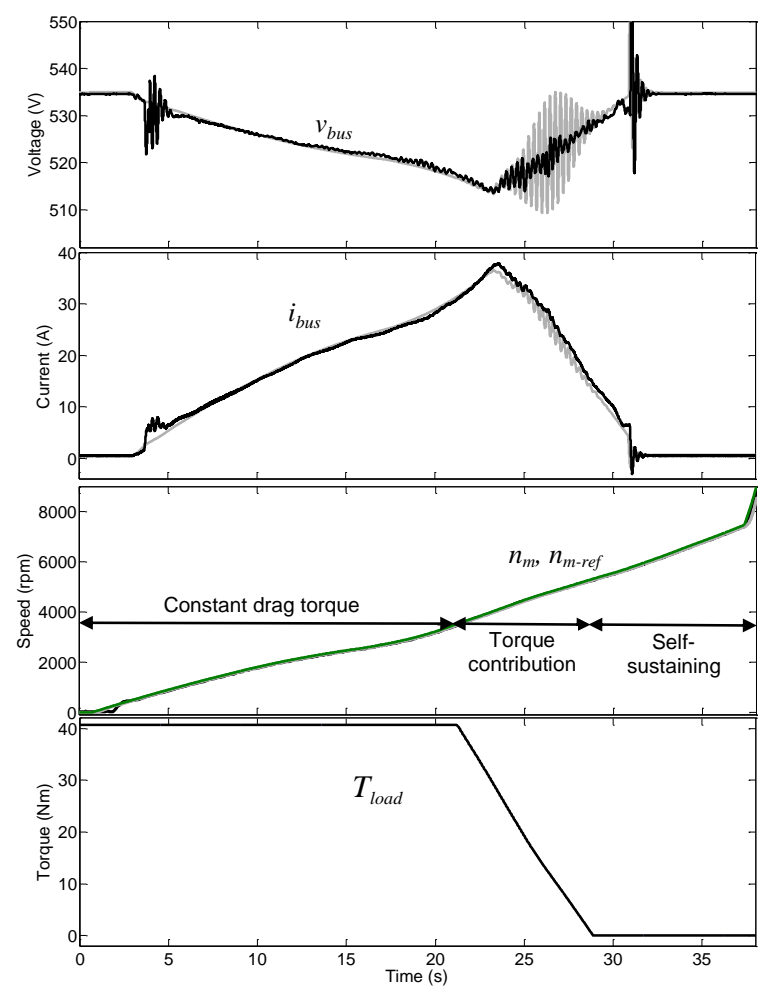

Fig. 12 Measured (black traces) and simulated response (grey traces) for an engine start profile

\section{CONCLUSION}

A system-level behavioural modelling technique is proposed for the motoring operation of a SRMD. The model reproduces the static and dynamic behaviour of the system in terms of its input-output signals and is parameterised by means of straightforward tests on the SRMD hardware. The model has been validated by comparing the measured and model responses for two tests, a constant acceleration test and a gas-engine start. It has been demonstrated that the model predicts properly the static and dynamic response of the system in both cases.

By combining an electro-mechanical power balance calculation with a look-up table for the system 
losses, and taking into account the acceleration limits of the drive, it was found that linear transfer functions were sufficient to represent the SRMD behaviour over the full operating range. Furthermore, variations in dynamic characteristics across the operating range could be accommodated using a polytopic approach [21], [22]. The modelling technique is generic and applicable to any electrical drive system providing straightforward experimental tests may be undertaken over the full operating window. No details of the drive design, either control, power electronics or electric machine, are required.

The SRMD motoring model can be used in conjunction with a system-level model of the generator operation [14] to form a system-level model of the starter generator system. The models can readily be combined as both output a DC current that is drawn or delivered to the DC-bus. The separate SRMD motoring model, or the combined motor and generator model, are both suitable for system-level studies to predict dynamic interactions between the SRMD and other power distribution subsystems, such as power electronic loads, generators or energy storage devices.

\section{REFERENCES}

[1] A. Griffo, J. Wang, "Large Signal Stability Analysis of 'More Electric' Aircraft Power Systems with Constant Power Loads" IEEE Trans. Aero. Electron. Systems, vol. 48, no. 1, pp. 477-489, 2012.

[2] M. Howse, “All Electric Aircraft”, Power Engineer, 17 (2003), pp. 35-37, 2003.

[3] K. Areerak, S.V. Bozhko, G.M. Asher, L. De Lillo, D.W.P. Thomas, "Stability Study for a Hybrid AC-DC More-Electric Aircraft Power System", IEEE Trans. Aero. Electron. Systems, vol. 48, no. 1, pp. 329-347, 2012.

[4] J.A. Rosero, J.A. Ortega, E. Aldabas, L. Romeral, "Moving Towards a More Electric Aircraft", IEEE Aero. Electron. Systems Maganize, vol. 22, no. 3, pp. 3-9, Mar. 2007.

[5] R. Todd, A.J Forsyth, "HIL Emulation of All-Electric UAV Power Systems", in Proc. of IEEE Energy Conversion Congress and Exposition (ECCE), pp. 411-416, 2009.

[6] C. A. Ferreira, S. R. Jones, W. S. Heglund, W. D. Jones, "Detailed Dsign of a 30-kW Switched Reluctance Starter/Generator System for a Gas Turbine Engine Application", IEEE Trans. Ind. Applicat., vol. 31, pp. 553-561, 1995.

[7] A. V. Radun, C. A. Ferreira, E. Richter, "Two Channel Switched Reluctance Starter/Generator Results," IEEE Trans. Ind. Appl., vol. 34, no. 5, pp. 1026$1034,1998$.

[8] N. Schofield, S. Long, "Generator Operation of a Switched Reluctance Starter/Generator at Extended Speeds", IEEE Trans. on Vehicular Technology, vol. 58, no. 1, pp. 48-56, 2009.

[9] Z. Chen, H. Wang, Y. Yan, “A Doubly Salient Starter-Generator with Two-Section Twisted-Rotor Structure for Potential Future Aerospace Application", IEEE Trans. Ind. Electron., vol. 59, no. 9, pp. 3588-3595, 2012.

[10] O. Ichinokura, T. Kikuchi, K. Nakamura, T. Watanabe, H. Guol, "Dynamic Simulation Model of Switched Reluctance Generator," IEEE Trans. Mag., vol. 39, no.5, part 2, pp. 3253-3255, 2003.

[11] C. Zhuping, L. Deliang, "Simulation of Switched Reluctance Starter/Generator System Based on Simplorer", in Proc. of the $8^{\text {th }}$ Int. Conf. on Electrical Machines and Systems (ICEMS), vol. 1, pp. 564-567, 2005.

[12] W. Ding, D. Liang, “A Fast Analytical Model for an Integrated Switched Reluctance Starter/Generator”, IEEE. Trans. Energy Conv. vol. 25, no. 4, pp. 948956, 2010.

[13] D. B. Wicklund, D. S. Zinger, "Voltage Feedback Signal Conditioning in Switched Reluctance Generation Systems", Proc. IEEE Appl. Power Electron. Conf. Expo (APEC), pp. 376-380, 2000.

[14] V. Valdivia, R. Todd, F. Bryan, A. Barrado, A. Lazaro, A.J. Forsyth, "Behavioural Modelling of a Switched Reluctance Generator for Aircraft Power Systems", IEEE Trans. on Ind. Electron., early version, DOI:10.1109/TIE.2013.2276768, 2013.

[15] C. Liaw, H. Chang, "An Integrated Driving/Charging Switched Reluctance Motor Drive using Three-Phase Power Module”, IEEE Trans. Ind. Electron., vol. 58, no. 5, pp. 1763-1775, 2011. 
[16] C. Moron, A. Garcia, E. Tremps, J.A. Somolinos, “Torque Control of Switched Reluctance Motors", ", IEEE Trans. Mag., vol. 48, no. 4, pp. 1661-1664, 2012.

[17] H.J. Brauer, M.D. Hennen, R.W. De Doncker, “Control for Polyphase Switched Reluctance Machines to Minimize Torque Ripple and Decrease Ohmic Machine Losses", IEEE Trans. Power Electron., vol. 27, no.1, pp. 370-378, 2012.

[18] H. Hannoun, M. Hilairet, C. Marchand, "Design of an SRM Speed Control Strategy for a Wide Range of Operating Speeds", IEEE Trans. on Ind. Electron., vol .57, no.9, pp. 2911-2921, 2010.

[19] L. Ljung, "System Identification: theory for the user, 2nd ed.", Prentice Hall, 1999.

[20] V. Valdivia, A. Lazaro, A. Barrado, P. Zumel, C. Fernandez, M. Sanz, "Black-Box Modeling of Three Phase Voltage Source Inverters for System-Level Analysis" IEEE Trans. Ind. Electron., vol. 59, no. 9, pp. 3648-3662, 2012.

[21] L. Arnedo, D. Boroyevich, R. Burgos, F. Wang, "Polytopic Black-Box modeling of DC-DC converters", in Proc. of IEEE Power Electron. Specialists Conf. (PESC), pp. 1015-1021, 2008.

[22] V. Valdivia, A. Barrado, A. Lazaro, C. Fernandez, P. Zumel, "Black-Box Modeling of DC-DC Converters Based on Transient Response Analysis and Parametric Identification Methods", in Proc. of IEEE Appl. Power Electron. Conf. (APEC), pp. 1131-1138, 2010. 